\title{
Insights into a Graduate Degree in Industrial Distribution Offered by Distance Education
}

\author{
Daniel F. Jennings ${ }^{*}$, Bharani Nagarathnam, Frederick B. Lawrence \\ Industrial Distribution Program, College of Engineering, Texas A\&M University, College Station, Texas, United States
}

Copyright $(2018$ by authors, all rights reserved. Authors agree that this article remains permanently open access under the terms of the Creative Commons Attribution License 4.0 International License

\begin{abstract}
Wholesale Distribution in the United States is a \$6 trillion dollar industry that includes 370,000 businesses that employ 6 million people. With evolving distribution business models, margin pressure, and an aging workforce, distributors are faced with a talent management crisis, especially with hiring, developing and retaining managers and developing a leadership pipeline. Traditionally, distributors promoted for their managerial and leadership positions based on tenure and prior job performance. With an increase in the need for business competitiveness, customer experience, value added services and innovative new solutions, distributors need to develop competency based mid-mangers who can effectively drive change and impact profitability.
\end{abstract}

Keywords Management Development, Leadership, Human Capital, Industrial Distribution

\section{Introduction}

The growth of a distribution organization does not rely solely on the distributor's geographic reach, physical assets, product selection, or access to capital. It also depends on its human capital. In fact, all organizations require human capital to accomplish their goals. Therefore, the organization's ability to manage its human capital is a key to its business success. Treating people as capital means recognizing them as an asset rather than as an expense item. While most wholesaler-distributors understand how to leverage financial and physical capital, when it comes to managing people, organizational leaders often find themselves struggling with attracting, developing and retaining key talent, managing and developing employees effectively or measuring the return on their human capital investment.

In 1998 many senior managers in industrial distribution firms who served on the Industry Advisory Board of the Industrial Distribution Program at Texas A\&M requested a graduate program for their managerial employees. Many of those managerial employees had come up through the ranks progressing from entry level employee to sales or operations positions before becoming a manager. While these employees had knowledge and experience in the products, services, customers and market, they lacked business acumen, understanding of competitive advantage and profitability (financial analysis) knowledge. These senior managers were also searching for a distribution focused education rather than a generic graduate program such as an MBA. The Industry Advisory Board members also expected that such a program should be flexible and convenient for their managers so that these managers did not have to leave their current job responsibilities. The Industrial Distribution program began the design of a distance learning graduate program focused on distribution in 1999 and received approval in 2001. The program was entitled the Master of Industrial Distribution (MID) and students enrolled as a cohort which is a group of students working together through the same academic curriculum. The first cohort was admitted in 2001. The cohort program was designed for working professionals with a minimum of five years of experience and consisted of three parts: residency week, global distribution course and trip and a capstone project. The program which has been continuously improved over the past fifteen years is a web-based, part-time graduate program and focuses on five areas: (1) using applied case studies, videos, interviews and podcasts, (2) teaching courses that have met the Quality Matters Course [1] design rubric standards (3) having industry executives to co-teach, (4) improving studentto-student and student-to-faculty interaction by using discussion boards to reinforce understanding, and (5) having mobile learning experiences through iPads, eBooks, and apps.

Wholesale Distribution in the United States is a \$6 trillion dollar industry with 370,000 businesses that employ 6 million people and accounts for about 6\% of the 2016 GDP (U.S. Census, 2016 [2]). Also, as depicted in Table 1, Wholesale Distribution is one of the top four sectors of the U.S. economy. 
Table 1. Key U.S. Sectors share of 2016 GDP

\begin{tabular}{|c|c|}
\hline Finance, Insurance, Real Estate & $20.6 \%$ \\
\hline Manufacturing & $11.7 \%$ \\
\hline Healthcare & $7.4 \%$ \\
\hline Wholesale Trade & $5.9 \%$ \\
\hline Retail Trade & $5.8 \%$ \\
\hline Construction & $4.2 \%$ \\
\hline Mining & $1.5 \%$ \\
\hline
\end{tabular}

Source: National Association of Wholesaler-Distributor

\section{Methods and Sample}

The area of study was the Master of Industrial Distribution (MID) degree offered by the College of Engineering at Texas A\&M University in a distance education format [3]. In recent years, research has been conducted to investigate trends in distance education [4]. Interestingly, this research has focused solely on individual distance education courses [5]. Research on distance education degree programs is almost non-existence [6]

The MID Program is a 30 hour credit distance education graduate degree and is a 21 month, part- time, lock- step, on line graduate program designed for working professionals. The Program focuses on Supply Chain Management, Logistics, Profitability, and developing a Competitive Advantage of distributors and manufacturers (suppliers) within industrial channels. The MID program involves immersive learning experiences that include a residency on the Texas A \& M campus, a global class and trip and a capstone project. The MID Program is designed to dramatically increase the student's ability to think globally, integrate trends, and acquire knowledge and to act strategically. The courses provide the critical skills and knowledge necessary for both the student and their company that can be immediately applied. Through the Program's lock-step approach to learning, students interact in a manner which provides new insights to them and broadens their personal and professional experiences. As a result, students can immediately apply the knowledge that has been gained from their MID courses to everyday challenges that are faced by the students in their workplace.

Students enrolled in the MID Program represent a diverse group of professional with a wide range of education and work experiences from their particular companies and their geographic locations. All students accepted into the MID program are required to submit certain information. Students have agreed that this information may be utilized to publicize the MID program [7].

Figure 1 describes the enrollment for the 2016 MID Class [8]
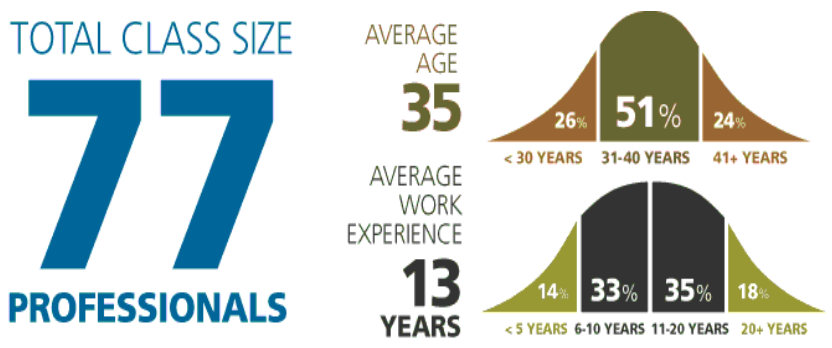

Figure 1. 2016 MID Enrollment

Table 2 presents the Courses and Degree plan for the MID Program by semester [9]

Table 2. Courses and Degree Plan

First Year

Residency Week (One Week in August)

\begin{tabular}{|c|c|}
\hline Course Name & Credit \\
\hline IDIS 611-Current Issues in Industrial Distribution & 3 Hours \\
\hline
\end{tabular}

Fall Semester (15 weeks on line)

\begin{tabular}{|c|c|}
\hline Course Name & Credit \\
\hline IDIS 624 - Strategic Relationships for Industrial Distributors & 3 Hours \\
\hline IDIS 614- Industrial Distributor Networks & 3 Hours \\
\hline
\end{tabular}

Spring Semester (15 weeks on line)

\begin{tabular}{|c|c|}
\hline Course Name & Credit \\
\hline $\begin{array}{c}\text { IDIS 644- Industrial Distributor Information and Technology } \\
\text { Management }\end{array}$ & 3 Hours \\
\hline IDIS 634- Quality Concepts in Industrial Distribution & 3 Hours \\
\hline
\end{tabular}

Second Year

Residency Week (One Week in August)

\begin{tabular}{|c|c|}
\hline Course Name & Credit \\
\hline $\begin{array}{c}\text { IDIS 621-Industrial Distributor Processes I } \\
\text { (Capstone Project) }\end{array}$ & 3 Hours \\
\hline
\end{tabular}

Fall Semester (15 weeks on line)

\begin{tabular}{|c|c|}
\hline Course Name & Credit \\
\hline IDIS 655 - Global Distribution & 3 Hours \\
\hline IDIS 664- Distribution Profitability & 3 Hours \\
\hline
\end{tabular}

Spring Semester (15 weeks on line)

\begin{tabular}{|c|c|}
\hline Course Name & Credit \\
\hline $\begin{array}{c}\text { IDIS 622- Industrial Distributor Processes II } \\
\text { (Capstone Project continued) }\end{array}$ & 3 Hours \\
\hline IDIS 674- Industrial Distribution Enterprise & 3 Hours \\
\hline
\end{tabular}

In summary, this research has described certain general information about the MID Program, while specifics are related to the 2016 class. That class included 77 students. Information was obtained from all 77 students based on their responses. 


\section{Industrial Distribution Degree Programs}

Wholesale distribution is one of the largest sectors of the U.S. Economy. There are about 15 universities in the U.S that offers undergraduate degrees in this area. Only Texas A\&M University offers a graduate program in Industrial Distribution. The program is designed as a flexible distance learning program to provide access to working professionals in the industry. The distance learning provides opportunity for distribution professionals from around the US and globe to be able to advance their careers.

The MID program also reduces barriers for students who are working professionals by providing comprehensive student services. The Master of Industrial Distribution student services team is dedicated to making the transition back to the classroom as smooth as possible, including those that have a full-time job, family and other studies. The program wants students to focus on their studies they take care of the rest. MID's dedicated student services team provides the following services:

- $\quad$ Course Registration

- $\quad$ Textbook \& course material delivery

- Residency Week logistics including accommodations

- $\quad$ Global trip logistics including accommodations \& in-country transportation

- Capstone project presentation \& graduation logistics including accommodations

- Technical support for eCampus or Blackboard Learn (the learning management system) courses

- $\quad$ Tuition \& fees billing checks and reminders

- $\quad$ Third party student sponsor payments (i.e. company direct fee payments)

- $\quad$ Assistance with Veteran benefits processing

- Assistance with international TAMU student services

\section{Learning Effectiveness}

All of the MID classes are designed to be asynchronous to meet the demands of a working professional. Students can login anytime and learn at their own pace during the semester. Student peer learning experience is enhanced through discussion boards and group projects.

Cohort model: The MID program only admits students in Fall semester as a cohort and all the students take the same classes and move forward together. The cohort model offers many learning advantages such as sense of community, peer support system, group activities and lifelong networking. Students are grouped into teams of 4 or 5 and remain as a group throughout their program. Many student groups not only actively collaborate on class work, but learn from each other's business/functional experiences.

Experiential Learning: The MID Program enhances learning effectiveness through multiple experiential learning activities. There is a Residency Week each August, the Global Distribution course \& trip during the second year and capstone project in the last semester. During Residency week, students are involved in case study problem solving exercises industry leader presentations and group solution development activities. During the global class and trip, the students work on a live project with a global company, visit their operations, interact with their leaders and professionals and develop recommendations for the project.

Capstone Project: MID students are required to select a capstone project, likely from their sponsor company and work closely with faculty and the Global Supply Chain Systems Laboratory (GCSL) researchers to deliver a high-value solution that can be immediately implemented. These projects provide invaluable preparation for professional work where students develop a strategy and timetable for work completion. The faculty and GCSL team guide students through the research project process, establishing a timeline and expectations with the firm, suggesting areas to investigate, helping students refine a problem, pointing out relevant resources, imparting relevant technical skills and knowledge, and commenting thoroughly on iterations of work, from initial drafts to the final product. Students will give an initial presentation of their work to the SCSL team and faculty for feedback and improvement suggestions before giving the final presentation. The MID student brings a Return-On-Investment to the firm with new best practices and a problem solving skill set that goes far beyond graduation. 


\section{Capstone Project}

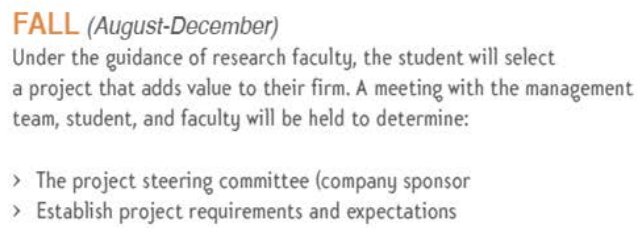

FALL (August-December)

Under the guidance of research faculty, the student will select a project that adds value to their firm. A meeting with the management team, student, and faculty will be held to determine:

The project steering committee (company sponsor

> Establish project requirements and expectations

SPRING (January-May)

From December to March students will conduct the research project and deliver the results to management, faculty and their peers between April and May.

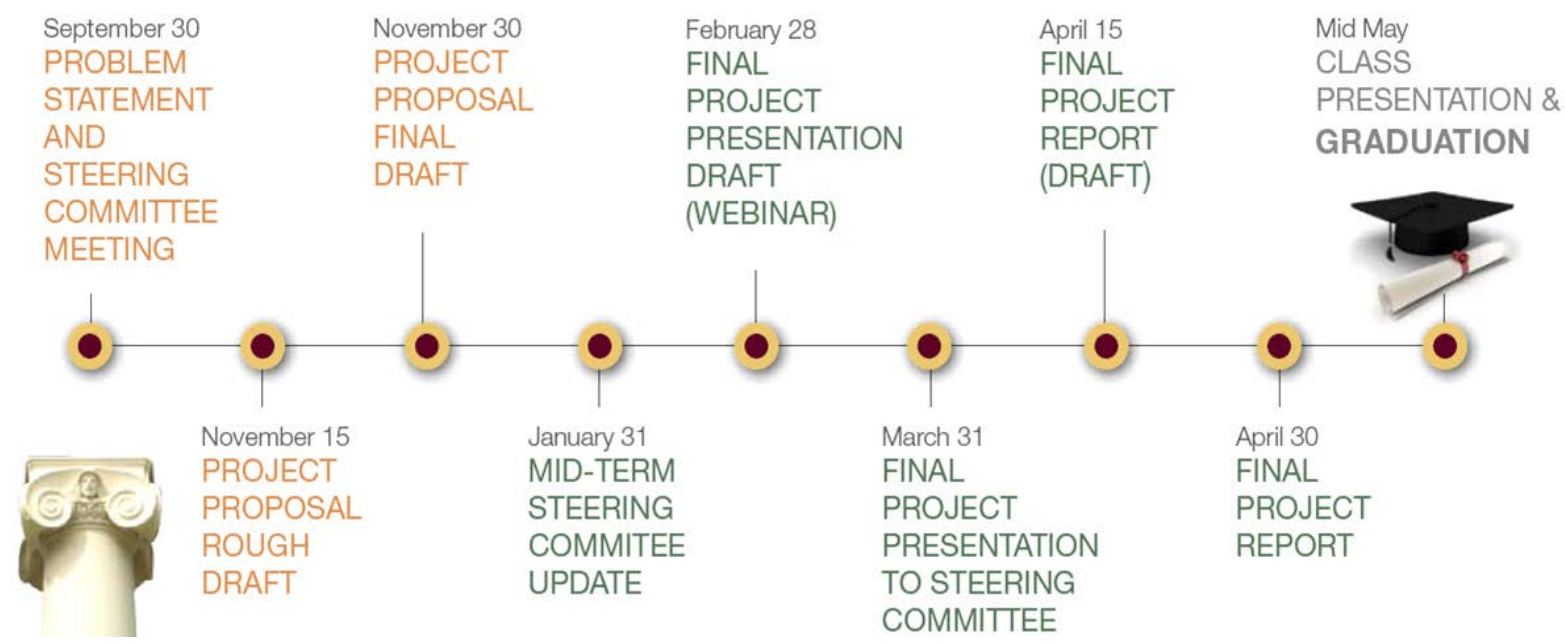

Figure 2. Capstone Project Timeline and Deliverables

\section{Quality Matters [10]}

In 2015, the MID program embarked voluntarily on the Quality Matters Program. The Quality Matters Higher Education Rubric is a set of 8 General Standards and 43 Specific Review Standards used to evaluate the design of online and blended courses. Unique to the Rubric is the concept of alignment. This occurs when critical course components - Learning Objectives (2), Assessment and Measurement (3), Instructional Materials (4), Course Activities and Learner Interaction (5), and Course Technology (6) - work together to ensure students achieve desired learning outcomes. As of May 2017, five of the courses has been through the formal review and has been certified as meeting or exceeding the QM metrics. Two other courses are being prepared to be go through formal review soon. The goal is to certify all ten courses by the end of 2017 and be the first and only graduate program at Texas A\&M to be Quality Matters certified.

Based on the 15 years of development and improvement, the Master of Industrial Distribution program has been awarded the following two awards. Additionally, the MID program is now the largest distance education program in the College of Engineering.

- 2016 21st Century Best Practice Distance Learning from the United States Distance Learning Association (USLDA) (USDLA, 2016). [11]

- 2016 Outstanding Commitment to Excellence and Innovation award from TxDLA (Texas Distance Learning Association) (TxDLA, 2016). [12]

\section{Cost Effectiveness:}

The MID program is similar to an online MBA for professionals geared specifically towards engineers. In Texas, the average cost of a professional MBA program is more than $\$ 90,000$, while the MID program only costs $\$ 48,000$ for TX residents and $\$ 58,000$ for out-of-state students. This cost not only includes tuition and fees, but it includes all books, two on-week residency weeks, an international trip, on-campus project presentations and all costs associated with graduation. The MID Program is also a proud supporter of Veterans. The MID program typically has about $15 \%$ of students who are Veterans. The MID Program works with the Veteran Services and Student Business Services at Texas A\&M to process their service (G.I Bill and Hazelwood) benefits. The MID program benefits mid-career working professionals to earn a relevant, specialized and cutting-edge education in a flexible cohort on-line environment that greatly enhances their skills and prepares them for managerial and leadership positions.

\section{Student Satisfaction:}

The MID Program is constantly working on improving the learning outcomes and student experiences. The program conducts the following surveys to collect information and uses it to enhance courses, content, experiences and services.

- $\quad$ Residency Week experience survey

- Individual end-of-semester course surveys

- Global trip experience survey

- $\quad$ Capstone project survey

- $\quad$ Exit interviews 
The above survey results are reviewed by the program management team. Course surveys are communicated to respective faculty for review and continuous course improvement.

Technology: One of the student services request over the past few years is to provide all books electronically since many of the students travel extensively and carrying along heavy books is inconvenient. We have worked over the past year to design, develop and implement a mobile leaning initiative with iPads for all incoming students starting August 2015. The course content includes eBooks, reading materials, videos, audio lectures and experiential learning exercises. The Master of Industrial Distribution courses are accessed through Texas A\&M eCampus and its accompanying mobile app.

\section{Faculty Satisfaction:}

The MID faculty has expressed considerable satisfaction in teaching MID courses, interacting with students, serving as their capstone project chairs, interacting with the student's managers and company leadership. Many faculties have also achieved scholarly publication in working with the MID students. Some faculties have also invited these students and industry professionals to speak in their undergraduate classes. The female MID students are also invited to campus to speak at the Society of Women in Industrial Distribution each semester.

\section{Continuous Improvement}

The MID program continues to improve the design, development and delivery. Some of the steps take include:

- Applied content development includes industry focused live case studies, videos, interviews and podcasts.

- Teaching enhancement include quality matters certification and the use of industry executives to co-teach classes

- Learning experience enhancement includes reflective discussion boards, group projects and peer-group learning.

- Content delivery through mobile learning experience with iPad, eBooks and apps.

\section{Exit Interviews \& Industry Advisory Board}

The MID Program also conducts a robust exit interview survey with about $90 \%$ completion rate. The feedback on program improvement recommendations, perceived learning, value of certain activities is evaluated every year and key themes are identified for improvement. The MID Program also has an active Industry Advisory Board consisting of 10 former student executives to review yearly updates and provide advice / recommendations for improvements. The advisory board meets every year in
May and receives periodic updates on the program activities.

\section{Learning Outcomes}

The following are the MID Program learning outcomes/objectives as well as measures in place to measure the learning outcomes.

\section{MID Program Outcomes/Objectives}

1. In-depth knowledge of industrial distribution

2. Graduates will have successful careers

3. Recognize need and ability of lifelong learning

4. Build an effective international competence

5. Graduates will be competent

6. Effectively function in multi-disciplinary teams

7. Graduates will be able to conduct applied industry research

8. Increase the application pool

9. Increase the diversity of the application pool

\section{Measures \& Findings}

1. Capstone research project

2. Real time case studies in global distribution

3. Exit Survey

4. Data on Applicant Pools

5. Sustainable competitive advantage exam

6. Departmental course outcomes

7. Alumni Survey

8. MID Industry Advisory Board Focus groups

9. Industry Advisory Board Focus groups

\section{Conclusions}

The distribution industry is challenged with talent development and retention. Distributors have an opportunity to hire, develop and retain their managerial talent through the effective use of the focused educational development programs. The Master of Industrial Distribution is one such graduate program designed for such an approach. In conclusion, the design, development and continuous improvement of a graduate program designed for working professionals in the distribution sector helps develop distributors' talent, operations and profitability.

\section{REFERENCES}

[1] Standards from the Quality Matters Higher Education Rubric, 5th Edition. Quality Matters; Retrieved from https://www.qualitymattersorg/sites/default/files/PDFs/Stan dards from the QM Higher Education Rubric pdf 
[2] U.S. Census Bureau (2017) Monthly and Annual Wholesale Trade; Retrieved from https://www.census.gov/wholesale.index html

[3] Texas A\&M Graduate Catalog (2017-18) Master of Industrial Distribution.

http://catalog.tamu.edu/engineering/technology, industrial distribution degree

[4] A. Bozkurt and S. Sezgin "Trends in Distance Education Research: A Content Analysis of Journals, 2009-2013" (2015) International Review of Research in Open and Distributed Learning, vol. 16, no. 1, pp. 332-334.

[5] A. Bozkurt and S. Sezgin "Trends in Distance Education Research: A Content Analysis of Journals, 2009-2013" (2015) International Review of Research in Open and Distributed Learning, vol. 16, no. 1, pp. 336-338.

[6] O. Zawacki-Richter and T. Anderson, "Online Distance
Education: Towards A Research Agenda" (2016) Open Learning. vol 30, pp 112.

[7] MID Student Handbook (2016). Department of Engineering Technology and Industrial distribution, Texas A\&M University.

[8] See note \#7

[9] See note \#7

[10] See note 31

[11] United States Distance Learning Association (2016), 2016 USDLA International Awards; Retrieved from https:// www.usdla. org/awards/2016-usdla-internatioal -awards-2/

[12] Texas Distance Learning Association (2016), Outstanding Commitment to Excellence and Innovation in Distance Learning (2016); Retrieved from http://txdla.org/Default.aspx/tabid=141 